\title{
Promoção de Saúde e Comensalidade: Um Estudo entre Residentes de Moradia Universitária
}

\author{
Hayda Josiane Alves ${ }^{1}$, Maria Cristina Faber Boog ${ }^{1}$
}

\begin{abstract}
Alimentação é um importante veículo de produção de saúde, porque perpassa tanto por fatores objetivos, ligados à alimentação, como o que e quanto se come, quanto subjetivos, relacionados aos significados do fato alimentar. 0 presente trabalho é um estudo qualitativo realizado com o objetivo de investigar aspectos subjetivos da alimentação de universitários residentes em moradia estudantil, com base na teoria das representações sociais de Moscovici. Para a coleta de dados foi empregada a técnica de grupo focal. As falas dos entrevistados trouxeram representações relativas à comensalidade, à produção de cuidado relacionado à alimentação e do tornar-se provedor da própria alimentação. 0 estudo das representações sociais circundando estes aspectos pode ser especialmente útil para o desenvolvimento de programas de promoção da saúde e educação nutricional.
\end{abstract}

Palavras-chave: alimentação - nutrição - promoção da saúde - representações sociais.

\section{Health Promotion and Commensality: Study among Students Living in a University Housing}

Feeding is an important issue in health production because of both objective and subjective factors. The former, deals with what and how much we eat and the latter, with the meanings of food and feeding. In order to investigate the subjective aspects of feeding in college students living in a student residence, this qualitative study used the technique of focal group in data collection and Moscovici's theory of the social representations for the symbolic content analysis. The statements collected revealed commensality representations, the concern about feeding and the sense of the subjects becoming food self-providers. The study of social representations regarding these aspects can be especially useful in developing programs of health promotion and nutritional education.

Keywords: feeding - nutrition - health promotion - social representations.

\footnotetext{
${ }^{1}$ D epartamento de Enfermagem / Faculdade de Ciências Médicas - FCM (UNICAMP)
} 


\section{Introdução}

O projeto de promoção da saúde, desencadeado em âmbito mundial a partir da Carta de 0 ttawa $^{1}$ que definiu os pré-requisitos para a saúde - paz, habitação, educação, alimentação, renda, ecossistema estável, recursos sustentáveis, justiça social e eqüidade, ampliou, para além de espaços institucionais, as oportunidades para a produção de saúde $^{2,3}$. D estaca-se que essa possibilidade não isenta o Estado do dever de garantir o acesso universal à saúde, enquanto um direito constitucional ${ }^{4}$, mas, sobretudo, supera o determinismo biológico da saúde e incorpora a idéia de um indivíduo com direitos, necessidades, valores, desejos, aspirações e subjetividades, tornando a própria condição humana como um dos fatores determinantes da construção social do processo saúde-doença 5 . A partir de então, o homem, a sua atual condição de vida e a possibilidade de melhoria passam a ser determinantes para produzir saúde.

A alimentação, como um aspecto da vida cotidiana, também é um veículo de produção de saúde. Porém, se tomarmos apenas o homem como unidade isolada, corremos o risco de simplificar este processo de produção de saúde em funções normativas e prescritivas relativas à alimentaçã $0^{6}$. A condição humana também é uma questão central no que concerne à alimentação e se faz presente não apenas no comportamento individual, mas principalmente na coletividade ${ }^{7,8}$. Neste caso, a função humanizadora da alimentação se expressa pela presença do outro, ou seja, através da comensalidade - o comer junto, o comer socialmente, que nos diferencia dos animais ${ }^{9}$. A comensalidade humaniza o fato alimentar, além de ampliar as possibilidades de buscar a produção de saúde para além de aspectos objetivos da alimentação, como o que e quanto se come $^{10}$. Aspectos subjetivos, como a escolha de com quem se come, os significados atribuídos aos alimentos e às refeições, a influência do grupo no campo das escolhas individuais, o cuidado dispensado ao preparo de alimentos, entre outros aspectos, podem agregar sentidos à promoção da alimentação saudável ${ }^{6,11}$.

Por tudo o que foi exposto, consideramos que a condição humana deve ser 0 ponto de partida para a produção de saúde e cuidado através da alimentação. O s sujeitos, tanto individuais quanto coletivos, podem ser considerados como unidades de referência para a ação governamental, assistencial e educacional no campo da saúde e da alimentação. Neste sentido, podem ser tomados como unidades transformadoras do espaço que ocupam, por intermédio da participação política ou da produção de saúde, através do cuidado consigo mesmo e com pessoas próximas. Ayres ${ }^{12}$ afirma que os sujeitos, como "seres autênticos, com suas necessidades e valores, capaz es de produz ir coisas e transformar sua própria história, estão no œentro de todas as propostas renovadoras" do campo da saúde.

Tomou-se como fundamento teórico para 0 estudo, a teoria das representações sociais de Moscovici ${ }^{13}$. Para ele, as representações sociais consistem em:

"... um corpo organizado de conhecimentos e uma das atividades psíquicas graças às quais os homens tornam inteligível a realidade física e social, inserem-se num grupo ou numa ligação cotidiana de trocas e liberam os poderes de sua imaginação..." (p.29)

Os núcleos simbólicos que estruturam práticas sociais, como a alimentação, podem ser utilizados para compreender o comportamento alimentar e os elementos que conduzem à sua manutenção ou modificação. Este conhecimento é importante para a formulação de propostas de intervenção no campo da saúde, visto que possibilita a construção de intervenções por meio de programas educativos que contemplem a totalidade do fato alimentar e não apenas aspectos nutricionais.

Tendo os conceitos acima apresentados como pressupostos teóricos para o estudo do comportamento alimentar, e a existência de estudos brasileiros que vêm apontando diversos problemas em relação à alimentação de estudantes universitários, como: ausência de refeições, especialmente desjejum, baixo consumo de frutas e leite e não apropriação da autonomia em prover e cuidar da própria alimentação ${ }^{14,10}$, pensou-se em estudar a alimentação de estudantes universitários sob esta perspectiva. 0 presente estudo foi então concebido com o objetivo de compreender as representações da alimentação 
entre estudantes residentes de uma moradia de universidade pública. Este espaço foi escolhido por ser um universo homogêneo tanto do ponto de vista das condições de sobrevivência, quanto da criação de hábitos e práticas de saúde e alimentação.

\section{Material e Método}

Foi realizado um estudo qualitativo, empregando-se a técnica de grupo focal, com sete estudantes de uma moradia estudantil - ME. A técnica de grupo focal permite a obtenção de dados de natureza qualitativa a partir de sessões grupais em que as pessoas que compartilham traços comuns, como por exemplo, faixa etária, ocupação, papel que representam na comunidade, discutem vários aspectos de um tema especifico ${ }^{15}$. Esta técnica pode ser empregada quando se pretende trabalhar com mudança de comportamento humano eeducação em saúde, pois possibilita a inserção de indivíduos na discussão e resolução de problemas ${ }^{16}$.

O grupo de sete estudantes constituiu uma subamostra selecionada por conveniência, de forma intencional, a partir de amostra probabilística de 100 universitários, residentes na ME, há no mínimo um ano, e com idade superior a 18 anos, que haviam participado de um estudo quantitativo no qual foram estudadas suas práticas alimentares ${ }^{10}$. Neste tipo de estudo, o aprofundamento e a abrangência de compreensão constituem os focos de interesse e 0 tamanho da amostra não decorre de necessidades matemáticas ${ }^{17}$.

Para o grupo focal foram selecionados estudantes de diferentes cursos de graduação e pósgraduação. As variáveis sexo, idade e comportamento alimentar tinham representação aproximada à existente no trabalho anteriormente citado. A escolha desta amostra foi condicionada à participação do estudo anterior ${ }^{10}$ e preenchimento dos critérios de inclusão: disponibilidade, concordância e interesse em participar do grupo focal. No momento da realização das entrevistas do primeiro estudo, 0 universitário era esclarecido sobre a existência de uma segunda etapa, o grupo focal, o qual já era mencionado no termo de consentimento.

A compra de alimentos foi critério estabelecido por Alves e Boog ${ }^{10}$, para classificar as práticas dos estudantes em individuais ou coletivas. Os estudantes que apresentavam comportamento classificado como individual realizavam compra coletiva apenas de sal, açúcar e óleo. Entre os de comportamento classificado como coletivo, essa compra era de pão, leite, frutas e hortaliças. Por último, os estudantes de comportamento misto eram os que apresentavam padrão de compra de alimentos intermediário entre os anteriormente citados.

A técnica de grupo focal exige que haja um moderador e um observador, além dos participantes. O moderador teve como função coordenar a discussão e incentivar a participação de todos, formulando questões, evitando o predomínio de um sobre os demais e conduzindo a discussão de modo que esta se mantivesse dentro dos tópicos de interesse: qual o significado que a alimentação passa a ter a partir do momento que o estudante deixa a casa dos pais; em que momento e como são realizados os cuidados com a alimentação; como os comportamentos alimentares se refletem na vida e como modificá-los quando isto se faz necessário.

0 encontro foi iniciado com uma atividade de aquecimento: a exibição de um vídeo². A arte, por desencadear emoção, faz aflorar sentimentos pertinentes ao tema que se deseja tratar e, por esta razão, foi utilizada para criar condições favoráveis à expressão dos componentes subjetivos da alimentação que se pretendia estudar ${ }^{18 .} 0$ grupo focal teve duração de 1 hora e 40 minutos. As discussões foram gravadas além de anotadas pelo observador. A discussão foi bastante intensa, não havendo liderança de um participante ou outro durante a discussão, de forma que todos puderam expressar claramente suas opiniões.

\footnotetext{
${ }^{2} \mathrm{O}$ vídeo continha recortes de quatro filmes:

O smosis Jones. Produção e direção Peter Farrelly e Bobby Farrelly. EUA; 2001 (videocassete).

Babete's Fest. Produção e direção: G abriel Axel. França; 1988 (videocassete).

Mostly Martha, EUA. Produção e direção: Sandra Nettelbeck, EUA; 2002. (videocassete).

Chocolat. Produção e direção: Lasse Hallström, EUA; 2000 (videocassete).
} 


\section{Resultados}

Após a organização e análise dos registros dos observadores, foram criadas três categorias que sintetizam os principais resultados: "0 tornar-se provedor" (núcleo representacional central); "a comida e sua magia" e "prazer e saúde podem coex istir num mesmo espaœo?" A apresentação destas categorias é precedida pela caracterização dos sujeitos.

\section{Caractenização dos sujeitos}

A caracterização dos sujeitos que participaram do grupo focal é apresentada no quadro I.

Quadro I - Caracterização dos estudantes participantes do grupo focal

\begin{tabular}{|cccccc|}
\hline Entrevistado (E) & Sexo & $\begin{array}{c}\text { Tempo na } \\
\text { moradia (anos) }\end{array}$ & $\begin{array}{c}\text { Idade } \\
\text { (anos) }\end{array}$ & Curso & $\begin{array}{c}\text { *Comp. } \\
\text { Alimentar }\end{array}$ \\
\hline A & F & 6 & 26 & Grad. Eng. Agríc. & Coletivo \\
B & M & 3 & 26 & G rad. Enferm. & Misto \\
C & M & 4 & 22 & Grad. Música & Individual \\
D & M & 2 & 24 & Grad. Medicina & Individual \\
E & M & 3 & 25 & D out. Filosofia & Individual \\
F & F & 2 & 26 & Mestr. Eng. Q uím. & Individual \\
G & M & 4 & 23 & G rad. Física & Individual \\
\hline
\end{tabular}

* Comportamento alimentar

Na apresentação de resultados, as falas serão precedidas pela letra " $E$ ", indicando que são expressões verbalizadas no grupo focal, seguidas pela letra correspondente à caracterização do sujeito no quadro acima.

\section{o tornar-se provedor como núcleo representacional central}

Tornar-se provedor é apropriar-se de todos os aspectos pertinentes ao próprio comportamento alimentar. Na discussão acerca do momento em que os participantes se percebem provedores, foram obtidas as seguintes respostas: quando se escolhe onde comer, o que comer, o que beber, "quando se leva um Nutri para comer" ou "quando se tem qualquer outro comportamento queinfluencieo teu hábito alimentar...", ou seja, o estudante se percebe provedor tanto no momento de aquisição como quando escolhe 0 que comer, onde e quando. Situação totalmente diferente da vida em família, quando tudo isto era preparado e ofertado principalmente pela mãe e eles não tinham participação nestes eventos.
Como núcleo estruturante do comportamento alimentar desses indivíduos, o tornar-se provedor trouxe representações sobre: 0 cuidado consigo mesmo e o cuidado dispensado por outras pessoas à sua alimentação; limitações percebidas para a realização de uma alimentação adequada e formação do comportamento alimentar, com ênfase nas pessoas e nos espaços que exerceram influência mais significativa neste processo. Sobre este aspecto, os entrevistados elegeram, de modo geral, um outro, geralmente a mãe, como a pessoa que controlava todos os aspectos da alimentação do estudante antes do ingresso na universidade. Neste papel, ela representa, sobretudo, a garantia da qualidade da refeição, fato não necessariamente primordial entre os estudantes, quando eles próprios assumem o papel de provedores.

Nas duas falas seguintes, pode-se observar uma certa preocupação com a qualidade da alimentação atual e a valorização da comida de casa, preparada pela mãe, como referência de uma alimentação saudável. 
E-C: "E u comia melhor em casa [comparado a $\mathrm{ME}$ ] por que a minha mãe fazia vários legumes, coisas assim, sabe? E eu acho 0 bandejão meio gorduroso (...) E u acho que eu mando bem...eu como as coisas crtas, eu sou um bom provedor...(...) mas tem dia que eu tenho até raiva de comer, sabe? Pô! T enho que estudar e agora vou ter que ficar comendo!"

E-A: N a minha casa tinha esse negócio de dieta, alimentação saudável (...) bolacha recheada não tinha (...) então... achei quetava sozinha (...) nessa eu engordei $10 \mathrm{~kg}(. .$.$) na$ minha casa minha mãe controlava. A alimentação era semprecontrolada (...) minha mãe não fazia muito doœ (...) mas daqui pra frente quero ter uma alimentação saudável.

Ao assumirem-se como provedores de sua alimentação, os estudantes passam a identificar dificuldades para conseguir alimentar-se bem, sendo bastante citadas: 0 tempo, o dinheiro, a falta de conhecimento sobre como preparar os alimentos e a dificuldade de acesso a produtos para manter a "alimentação querida":

E-D: “... Bem são várias variáveis. Tempo, dinheiro, dificuldade de coz inhar, vocêtêm que lavar... M as ao mesmo tempo é um prazer.

E -G : "C onsiderando meu aspecto financeiro, eu acho que eu faço o que eu posso (...) poucas pessoas aqui sabem cozinhar (...) porque aqui éa cultura do miojo (...) 0 macarrão já é uma evolução!

E-B: "E u sinto muita falta da minha casa lá em M inas porque na minha casa plantava, né? Tinha horta na minha casa (...) então era aquela satisfação, né? V oœê pegava fazia sua salada (...) é totalmente diferente que pegar no bandejão ou comprar mesmo!" U ma cisa que mudou bastante é os produtos que tem aqui, por ex emplo, pão sovado, se você acha, tem que ir longe buscar (...) são vários outros produtos que não tem, então tive que mudar totalmente os hábitos".

A experiência de tornar-se provedor contribuiu para re-significar também as práticas de comensalidade nos finais de semana. A atividade de cozinhar não foi apresentada como parte do dia-adia, tendo sido caracterizada mais como uma atividade de "fim de semana", ou seja, uma atividade embutida de arte e "magia", destinada à comemoração, confraternização, ludicidade, hospitalidade, ao lazer e à visita de amigos, enfim, impregnada de certo estado de espírito. Neste sentido, os estudantes assim se expressaram:

\section{E-D: "a alimentação é prazer e arte (...) envolve as cores, (...) misturar temperos". \\ E-F: "se você não tiver bem, não cozinha legal!" (...) "E u gosto que as pessoas venham ex perimentar uma coisa legal que eu fiz (...) sozinho, só prá mim, não dá pique cozinhar, eu omo qualquer coisa...".}

Nos finais de semana o Restaurante Universitário - RU não oferecia alimentação. Estes eram os dias em que os estudantes mais cozinhavam e desenvolviam estratégias para prover alimentação. D urante a semana, os estudantes realizam as refeições no Restaurante Universitário, tanto pelo baixo preço e facilidade de acesso a uma alimentação significada por eles como saudável, representação embutida na expressão "refeição balanceada", quanto por esta rotina estar impregnada na cultura alimentar do universitário. Os depoimentos abaixo contêm estas significações, expressando como "o outro" garante a qualidade da alimentação:

E-E "ninguém come em casa [moradia] no dia-a-dia comum, todo mundo come no bandejão!"

E-C “... sei que no refeitório tem uma nutricionista, sei que elas trabalham bem... ela estudou para isso, ela sabe 0 que faz (...) se não tivesse uma dieta balanceada no bandejão dificilmente eu ia comer lá todos os dias.(...) acho que bandejão não éopção não, é uma necessidade!"

E-D “... eu priorizo fazer pelo menos uma refeição no bandejão, para garantir pelo menos uma alimentação boa no dia..." 


\section{A magia do "outro"}

A segurança de estar se alimentando bem é construída sobre um sistema de crenças relativas a quem prepara ea quem orienta condutas alimentares. A valorização do poder do outro érepresentada tanto na "magia" da comida, como na concepção do outro como o "feiticeiro" capaz de orientar uma alimentação que promova tal "magia". Não se está falando aqui de um comportamento racional, apoiado sobre análise de competência técnica, mas efetivamente na crença no poder de outra pessoa para operar mudanças na qualidade do alimento ou da alimentação. Nos exemplos abaixo, a nutricionista, o médico, o educador físico, a mãe e uma tia são igualmente apontados como detentores desse "poder", no caso os "feiticeiros":

E-A “já procurei a nutricionista (...), já pedi dieta balanceada pro médio... eu sei 0 que é crto, 0 que eu tenho que comer...".

E-C "quando as pessoas vão na academia, elas passam a comer melhor (...) e a cuidar mais do corpo, porque ele [profissional da academia] dá dicas, por ex emplo: elefalou pra eu comer ovo prá caramba prá ficar forte e eu passei a comer ovo prá caramba..." (...) se eu vejo 0 cara todo bombado e ele fala prá eu fazer alguma ooisa prá ficar forte igual ele eu faço...".

E-B “aprendi a cozinhar 0 básico em casa, œm a minha mãe (...) minha tia ensinou algumas coisas também, para não passar fome".

E-E "têm coisas que minha mãe faz, que aprendi a comer e gostar durante a vida e são ex tremamente saudáveis (...)

Em concordância com o que foi mencionado acima, E-G relata: "uma mãenão vai ensinar alguma cisa que não é saudável, né cara!".

\section{O prazere a saúde podem coexistirnum mesmo espaço?}

Sobre esta questão, houve posicionamentos divergentes para justificar ambas as opções, saúde ou prazer como questões antagônicas. Comer com prazer poderia excluir a possibilidade de classificarse como um bom provedor:

E-C: "Prazer e saúde são antagônicos pra mim".

E -A : "A cho que não sou boa provedora porque eu opto pelas guloseimas (...) quem ome por saúde é um bom provedor".

A primazia do prazer ou da saúde foi uma questão polêmica que permeou quase toda a discussão, pois, para alguns, quem se preocupa com a saúde é um bom provedor da alimentação, mas, para outros, "quem oome por saúde vive 100 anos de uma vida sem graça, enquanto poderia viver 90 anos de uma vida regada ao praz er" (E-G). Constatações similares estão presentes em escolhas simples do dia-a-dia, como a de um estudante ao relatar que prefere "não pagar ano reais num marmitex, se é possível com mesmo dinheiro, comprar uma lasanha, que é muito mais gostosa!" (E-H). Por outro lado, "ex istem alimentos que podem ser saudáveis e são gostosos", acrescenta E-E, ao citar a sopa de leite quesua mãefaz, ou E-H ao relatar quejá comprou "lasanha com frango, brócolis, espinafre e outras coisas saudáveis..."

O utra questão polêmica para o grupo foi aquela que tratou o momento em que está presente o prazer de comer ou o prazer de sentir-se bem esteticamente. A segunda opção, segundo muitos dos participantes, só é possível a partir da restrição do que e do quanto se come. As falas abaixo exemplificam estas questões:

E-E: "A cho que na alimentação ex istem vários praz eres... ex iste o praz er de comer e 0 prazer de você se sentir bem, de voốaparentar esteticamente bem; estar fisicamente bem esse é um praz er legal... você estar bem malhado, estar bem, definido, este é um prazer gostoso que você vai ver toda hora não só no momento da refeicão... já 0 prazer de omer tá ali no momento que você come..."

E-A: "Como eu como mais pela gula, pra mim é prazer de comer ou o de me sentir bem (...) porque eu não vou ser feliz comendo 
pouco.... então não vou viver comendo pouco... mas acho que eu deveria parar de omer (...) mas eu não estou faz endo nada para emagrecer, então eu não posso redamar! M as quando eu tô me achando muuuuito gorda, daí eu paro e fecho a boca..."

No decorrer da discussão surgiu, entre os participantes, uma associação entre a companhia, durante a refeição, o prazer e a paixão, que remetem à relação entre sexualidade e alimentação. Sobre este aspecto E-B diz:

"comer em boa companhia se pareœ muito com estar apaix onado". Para este participante, "ex isteuma construção cultural e social que é refletida pelo organismo numa ação hormonal, el evação dos níveis de serotonina, em ambos os casos, no comer e na paix ão" . Concluindo, E-B explica: “... na verdade 0 social influencia o hormonal. Porque se você começa a comer junto com uma pessoa, vai começar a liberar mais hormônio, serotonina (...) primeiro, eu sinto o prazer de tá conversando com ela, e também sinto 0 prazer de tá comendo, então quando eu como junto om ela, eu junto as duas coisas (...) eu junto os dois prazeres (...) e 0 organismo sabe disto, né? Se ele sabe disto, ele vai querer cada vez mais que eu faça isso."

\section{Discussão}

As falas presentes neste estudo refletem que o preparo da comida não é algo merecedor do "escasso" tempo na vida de um estudante universitário. Esteé um aspecto presente em diversos estudos que abordam a influência da globalização na mudança dos estilos de vida e, conseqüentemente, no comportamento alimentar, em especial na alimentação urbana ${ }^{19,20,21}$. 0 ato de preparar refeições, com o propósito de efetivamente prover um cuidado, adquire importância secundária, quando comparado a outros aspectos da vida universitária muito mais instigantes para os jovens. No calor da discussão no grupo focal, a valorização deste ato é resgatada apenas quando remonta a referências familiares ${ }^{22}$, não pelo valor nutricional das preparações, mas devido ao valor afetivo. As falas sobre este aspecto denotam que prover e cuidar da alimentação não estão, a priori, incorporados à vida na universidade como algo de importância e de valor ${ }^{10}$.

Entretanto, a referência familiar através da comida está ligada a uma representação de "individualidade", onde predominam lembranças, afetos e ensinamentos únicos e individuais de uma memória familiar, pois a família geralmente é o berço do cuidado com a alimentação. Mintz ${ }^{23}$, ao discutir traços da nossa memória geracional em relação à comida, lembra que nossas atitudes sobre este aspecto são normalmente aprendidas cedo e bem, e são inculcadas, em geral, por adultos afetivamente significativos, o que confere ao nosso comportamento alimentar um poder afetivo duradouro. Porém, cabe questionar se no mundo moderno este sentimento é tão duradouro assim, pois outras prioridades têm ocupado o tempo destinado ao cuidado com a alimentação. Isto individualiza 0 comportamento alimentar e deve ser tratado como um poderoso mecanismo para a adoção de diferentes práticas alimentares. $\mathrm{O}$ u seja, essa dinamicidade pode favorecer a introdução tanto das práticas veiculadas pelos programas de educação nutricional, quanto aquelas bombardeadas através das propagandas. Enfim, é um espaço aberto a todo tipo de influência.

As lembranças significam para alguns um "controle excessivo" sobre o que se come, visto que as "mães", provavelmente, controlavam de fato a entrada de produtos industrializados e preparações prontas no espaço alimentar doméstico, enquanto para outros, estas mesmas lembranças representam a vivência da cumplicidade familiar ao se tratar da alimentação como forma de cuidado e, neste último caso, acontece uma mistura entre lembranças familiares e cuidado. A família é lembrada através da alimentação e o cuidado com a alimentação é uma referência de família. A existência de uma representação não exclui a outra, elas podem se somar ou representar diferentes momentos da convivência familiar. Alguns elementos ligados à representação das lembranças familiares relacionadas à comida são resgatados e manipulados pela mídia, para conferir atributos simbólicos aos alimentos industrializados.

A maneira com que o indivíduo encara o fato de tornar-se provedor também é originada destas 
representações. Para alguns o tornar-se provedor é "estar livre" desse controle relacionado à alimentação e à padronização de horários, para outros é o saudosismo da vivência familiar e para outros ainda é a apropriação de uma nova responsabilização, como se fosse uma nova fase: 0 cuidado consigo mesmo. Estas representações também são dinâmicas e podem se sobrepor em diferentes momentos da vida desses universitários.

Em todos estes casos coexistem, no ambiente de moradia estudantil e na vida universitária, limitações para 0 desenvolvimento de práticas de cuidado relacionadas à alimentação como: novas demandas relativas ao emprego de seu tempo, dificuldades financeiras, falta de locais disponíveis para se alimentar e comprar alimentos, dificuldade de estabelecer periodicidade para as compras de perecíveis e não perecíveis, entre outras condições inerentes à situação nova de prover a própria alimentação. Estes fatores expressam ainda tendências de valorização de certos produtos ou dietas, que se configuram em novos padrões no campo das escolhas alimentares. 0 ambiente universitário, a situação de moradia, rotina alimentar num RU e a maneira com que 0 estudante lida com esta vida fora da casa dos pais são elementos que transformam o comportamento alimentar e induzem a uma re-significação da própria comensalidade, das funções da alimentação e do cuidado consigo mesmo através da alimentação. Para os estudantes, tornar-se provedor significa apropriar-se, através da alimentação, do cuidado consigo mesmo.

D esvendar questões tão humanas através do fato alimentar exige, nesta perspectiva, que se amplie também o olhar para as práticas dos sujeitos vinculadas à alimentação e ao cuidado. Práticas sociais como a alimentação não podem ser analisadas somente do ponto de vista da ingestão adequada de nutrientes, mas precisam ser compreendidas a partir do contexto em que a alimentação se insere.

Uma abordagem que oferece um modelo teórico para sistematizar o estudo da alimentação de forma abrangente é o conceito de espaco social alimentar. De acordo com Poulain e Proença ${ }^{11}$, o espaço social alimentar permite 0 estudo da alimentação como objeto sociológico total, conceito estabelecido pelo sociólogo Mauss para referir um objeto que "coloca em movimento a totalidade da sociedade e suas instituições". Estes autores conceituam espaço social alimentar como a zona de liberdade - situada entre os limites biológicos e as opções oferecidas pelo ambiente e pela cultura - dada aos "comedores humanos", que é marcada por condicionantes fisiológicos, biológicos, ecológicos e determinantes culturais.

Esta orientação amplia as possibilidades de produção de saúde tanto na esfera individual, quanto coletiva, visto que o comportamento alimentar pode ser considerado a partir da existência de determinantes biológicos, ecológicos, econômicos e culturais emaranhados no espaço físico e cultural, e nos sujeitos individuais e coletivos, que os significam e codificam. Esta perspectiva traz certas instabilidades ao campo da produção de saúde, pois 0 fenômeno alimentar adquire subjetividade, complexidade e dinamismo, colocando em movimento tanto a percepção dos sujeitos sobre seu comportamento alimentar, quanto às instituições e os saberes dos profissionais da áreapara lidar com a multidimensionalidade do fenômeno alimentar ${ }^{6,11,20,22}$. Por outro lado, a partir deste referencial teórico, fica mais fácil compreender porque saberes científicos herméticos, em núcleos de conhecimento não articulados entre si, não são capazes de alcançar a função totalizante da alimentação. Além disso, intervenções externas e deterministas aos indivíduos, reguladoras do corpo biossocial e prescritoras de regras de viver saudável, não contemplam a produção de saúde a partir do próprio indivíduo no momento em que este toma para si 0 cuidado com a saúde ${ }^{24}$. A alimentação sofre a influência de outros sujeitos (familiar, amigo, vizinho, etc...) e de redes sociais (escola, academia, etc...) no direcionamento de condutas de viver. Estas também são esferas produtoras (ou não!) de saúde e cuidado. 0 cuidado é um ponto de destaque para a produção de saúde a partir da alimentação, porque se expressa como um modo de viver/ sobreviver e como uma expressão de interesse e afeto consigo mesmo e com as pessoas próximas ${ }^{25}$.

Isto é especialmente importante nas sociedades modernas, quando freqüentemente lidamos com indivíduos que não olham verdadeiramente para si e muito menos abraçam a 
responsabilidade pelo autocuidado. Talvez isto explique porque hoje exista um espaço, para 0 "personal diet" ou "personal trainer", na medida em que se precisa de um outro para prover cuidados básicos inerentes à vida. A propósito também da contemporaneidade, a alimentação de final de semana, quando os estudantes mais cozinham, vem se revelando como outra face da alimentação moderna: o apetitoso espetáculo visual. Esta é uma nomeação dada por Sant'Anna ${ }^{26}$ à cozinha fashion das cores e dos preparos inusitados que, junto à maravilhosa tecnologia dos eletrodomésticos, originados da expansão do american way of life, ingressa a cozinha no terreno da moda. Neste sentido, cozinhar aparece muito mais ligado a um espetáculo visual esporádico do que ao cuidado diário com a alimentação e consigo mesmo. Esta orientação também esteve presente na fala dos participantes ao afirmarem que cozinhar na moradia é "coisa de final de semana".

Sobre a magia da comida, destaca-se que seu conteúdo simbólico não está ligado apenas ao preparo das refeições, como destacou Sant'Anna ${ }^{26}$, mas também ao significado do efeito da comida e ao valor que possui quem a prepara ou orienta condutas alimentares. Segundo Lévi-Strauss" ${ }^{27}$, em "O feiticeiro e sua magia”, a eficácia da magia implica em sua crença. D este modo, um fenômeno de ordem social pode penetrar no imaginário de diversas maneiras e até alterar o organismo através do comportamento, mas para isso as premissas são: a crença do feiticeiro em sua magia, do doente no feiticeiro e da comunidade no feiticeiro. Os profissionais das academias também são valorizados por deterem um determinado poder que viabiliza a conquista de um corpo bonito, saudável e, sobretudo, desejável. A presença feminina apresenta-se como outro importante fator nesse universo, no qual se sobressaem mães, avós e tias pelos conhecimentos geracionais ensinados algum dia.

O possuidor da receita "mágica" das boas práticas, o "feiticeiro" simbólico, foi personificado nos profissionais de saúde que oferecem 0 "aval técnico" para execução de dietas e mudanças de comportamento, o que justifica o fato deles serem procurados quando surge algum problema de saúde, ocasionado por má alimentação ou quando se pretende emagrecer. Entretanto, até que ponto as orientações oferecidas pelos profissionais de saúde contêm elementos que totalizam o fato alimentar, contextualizando-o em determinada realidade? Estudos realizados no Brasil evidenciam que a abordagem efetuada pelos profissionais de saúde sobre questões alimentares apresenta limitações importantes. Estas relacionam-se tanto à formação acadêmica e prática vivencial insuficientes para abordagem desta questão ${ }^{28}$, quanto a problemas vinculados à "biologização do fato alimentar", apontada por Silva ${ }^{29}$, quando afirma que para alguns profissionais de saúde o corpo é o domicílio de substâncias químicas - nutrientes dos alimentos, os quais se sobressaem nas orientações nutricionais, em detrimento de outros aspectos, no mínimo tão relevantes quanto os nutricionais, se pensarmos na qualidade de vida de forma ampla.

A "magia" exercida pelo outro foi observada ainda na fala do estudante que relaciona comida com paixão, situação em que as relações interpessoais são saboreadas e prazerosamente desfrutadas como as próprias comidas que servem à celebração do encontro ${ }^{30}$.

\section{Conclusões}

Concluímos que o tornar-se provedor da alimentação é núcleo estruturante de diversos saberes e significados relacionados ao nascimento de uma prática social: o cuidado com a alimentação. A representação de alimentação entre os estudantes da $\mathrm{ME}$, vinculada ao tornar-se provedor, não circunda apenas questões de saúde, mas principalmente percepções de si mesmo, através das representações em que o corpo é o foco de ação. Todavia, a preocupação com o corpo, mesmo que apenas por razões de ordem estética, é um importante canal para intervenções de educação em saúde. Porém, estas devem envolver a totalidade do fato alimentar, especialmente os elementos objetivos e simbólicos revelados através de práticas alimentares, para que sejam adequadas a uma dada realidade.

Foi destacada a importância dos profissionais de serviços de saúde e da academia, enquanto orientadores de condutas alimentares e das mães enquanto provedoras de uma alimentação saudável. 
O restaurante universitário foi colocado como uma necessidade para a provisão de alimentação durante a semana.

A comensalidade, um potencial humanizador do fato alimentar através da partilha, é algo restrito aos finais de semana, ou seja, algo não rotineiro. Isto acontece também com a incumbência pelo preparo da própria refeição, uma situação especialmente presente no final de semana, sendo que, durante a semana, isto é delegado a alguém, quando a saúde tem primazia sobre 0 prazer. Prazer e saúde foram considerados como fenômenos antagônicos nas práticas alimentares.

Tanto as lembranças familiares quanto a convivência com outras pessoas num ambiente de ME têm um importante papel na significação do fato alimentar e na construção de representações acerca de mudanças no padrão alimentar: incorporação de novos alimentos, comer e realizar preparações em novos espaços, valorizar ou desqualificar alimentos, refutar ou resgatar significados relativos a alimentos e preparações. Isso demonstra que as representações a respeito da comensalidade e do comportamento alimentar individual/ coletivo constroem, resgatam e rejeitam determinadas práticas alimentares. Este fato é especialmente importante para 0 desenvolvimento de projetos de promoção à saúde e educação nutricional, visto que direcionam o foco de atuação dos profissionais de saúde para aspectos bastante peculiares das comunidades as quais pertencem.

\section{Referências Bibliográficas}

1. O rganización Panamericana de La Salud (OPAS). Carta de Ottawa, 1986.[citado em 2002 nov 28]. Disponível em http:/ / opas.org.br/ promoção

2. Buss PM. Promoção de saúde e qualidade de vida. Ciência e Saúde Coletiva. 2000; 5(1): 163-77.

3. Buss PM. Uma introdução ao conceito de promoção à saúde. In: Czeresnia D; Freitas CM, organizadores. Promoção da Saúde: conceitos, reflexões e tendências. Rio de Janeiro: Fiocruz; 2003.

4. Brasil, 1988. Constituição da República Federativa do Brasil, promulgada em 5 de outubro de 1988. 29 ed. São Paulo: Saraiva; 2002.

5. Paim JS. A reforma sanitária e os modelos assistenciais. In: Rouquayrol MZ (org) Epidemiologia \& Saúde. 4 ed. Rio de Janeiro: Medsi; 1994.

6. Diez Garcia RW. Representações sociais da alimentação e saúde e suas contribuições no comportamento alimentar. PHYSIS: Rev Saúde Coletiva. 1997; 7: 51-68.

7. Poulain JP. Sociologias da alimentação: O s comedores e o espaço social alimentar. Florianópolis: Editora da UFSC; 2004.

8. Scholliers P. Food, drink and identity: cooking, eating in Europe since the middle ages. New York: Oxford; 2001.

9. Flandrin J, Montanari M. (org). História da Alimentação. 2ed. São Paulo: Estação Liberdade; 1998.

10. Alves HJ, Boog MCF. Comportamento alimentar em moradia estudantil: um espaço para promoção da saúde. Rev. Saúde Pública. 2007; 41(2): 197-204.

11. Poulain J-P, Proença RC. O espaço social alimentar: um instrumento para estudo dos modelos alimentares. Rev Nutr. 2003; 16(3): 356-86.

12. Ayres JRCM. Sujeito, intersubjetividade e práticas de saúde. Ciência e Saúde Coletiva. 2001; 6: 63-13.

13. Moscovici S. Representações sociais da psicanálise. Rio de Janeiro: Zahar; 1978.

14. Vieira VCR, Priore SE, Ribeiro SMR, Franceschini SCC, Almeida LP. Perfil socioeconômico, nutricional e de saúde de adolescentes recém-ingressos em uma universidade pública brasileira. Rev Nutr. 2002;15(2):273-82.

15. Whestphal MR, Bogus CM, Faria MM. Grupos Focais: Experiências Precursoras em Programas Educativos em Saúde no Brasil. Boletin de la O ficina Sanitária Panamericana. 1996; 6: 472-482.

16. Basch CE. Focus group interview: an 
underutilized research technique for improving theory and practice in health education. Health Education Quarterly. 1987; 14: 411-48.

17. Minayo MCS. O Desafio do Conhecimento: Pesquisa Qualitativa em Saúde. São Paulo: Editora Hucitec/ Rio de Janeiro: ABRASCO ; 1994.

18. Duarte JR JF. Por que arte-educação? 10ed. Campinas: Editora Papirus; 2000.

19. Grácia-Arnaiz M. Paradojas de la alimentación contemporánea. Barcelona: Icária -Institut Català d’Ántropologia; 1996.

20. D iez Garcia RW. Prática e comportamento alimentar no meio urbano: um estudo no centro da cidade de São Paulo. Cad Saúde Pública. 1997; 13 (3): 455-67.

21. Bleil SI. O padrão alimentar ocidental: considerações sobre mudança de hábitos no Brasil. Cadernos de D ebate. 1998; 6: 1-25.

22. Diez Garcia RW. Reflexos da globalização na cultura alimentar: considerações sobre as mudanças na alimentação urbana. Rev Nutrição. 2003; 16(4): 483-92.

23. Mintz SW. Comida e antropologia: uma breve revisão. Rev Bra de Ciências Sociais. 2001;16: 31-47.

24. Carvalho SR. O s múltiplos sentidos da categoria "empowerment" no projeto de promoção à saúde. Cad Saúde Pública. 2004; 20(4):1088-95.

25. Waldow VR. Cuidado humano: o resgate necessário. Porto Alegre: Editora Sagra Luzzato; 1999.
26. Sant'Anna D B. Bom para os olhos, bom para o estômago: o espetáculo contemporâneo da alimentação. Rev Pro-posições. 2003; 14: 41-61.

27. Lévi-Strauss C. 0 feiticeiro e sua magia. In: Antropologia Estrutural. Rio de Janeiro: Tempo Brasileiro; 1973.

28. Boog MCF. Educação nutricional em serviços públicos de saúde. Cad Saúde Pública. 1999; 15(2): S139-S47.

29. Silva DOE, Recine EGIG, Queiroz EFO. Concepções de profissionais de saúde da atenção básica sobre a alimentação saudável no Distrito Federal, Brasil. Cad Saúde Pública. 2002; 18(5): 13671377.

30. Matta, R. O que faz o Brasil, Brasil? Rio de Janeiro: Rocco, 1994.

\section{Autores}

Hayda Josiane Alves - Aluna de mestrado do D epartamento de Enfermagem / Faculdade de Ciências Médicas - FCM/ UNICAMP

Maria Cristina Faber Boog - Professora D outora do Departamento de Enfermagem / Faculdade de Ciências Médicas - FCM/ UNICAMP. Correspondência: Caixa Postal 6111, Campus Universitário Zeferino Vaz D epartamento de Enfermagem / Faculdade de Ciências Médicas. Universidade Estadual de Campinas-UNICAMP. Campinas-SP - CEP: 13081-970 - Telefone: (019)3521-8836 e 3521-8820 - E-mail: crisboog@fcm.unicamp.br - Financiado pela Fundação de Amparo à Pesquisa do Estado de São Paulo (FAPESP - Processo 03/ 08682-1) 